\title{
РОЛЬ И ЗНАЧЕНИЕ МАРКЕТИНГОВЫХ СРЕДСТВ В ПОВЫШЕНИЕ ЭФФЕКТИВНОСТИ ПРОИЗВОДСТВЕННЫХ ПРЕДПРИЯТИЙ
}

\author{
Маматкулова Ш.Ж. \\ Самаркандский институт экономики и сервиса, \\ к.э.н., доцент кафедры маркетинга.
}

\begin{abstract}
Аннотация. В данной статье рассматривается основные инструменты маркетинга в развитии производства и сбытовой деятельности, значение маркетинговых средств в повышение эффективности производственных предприятий.
\end{abstract}

Ключевые слова: маркетинг, товар, реклама, фактор, «изделий и услуг», тактических задач, цель, ценность.

Маркетинг - одна из основополагающих дисциплин для профессиональных деятелей рынка, им нужно знать, как описать рынок и разбить его на сегменты, как оценить нужды и запросы, предпочтения потребителей в рамках целевого рынка. Как сконструировать и испытать товар с нужными для рынка потребительскими свойствами. Как посредством цены донести до потребителей идею ценности товара. Как выбрать умелых посредников, чтобы товар оказался широко доступным и хорошо представленным. Как рекламировать и продвигать товар, чтобы потребители знали и хотели его приобрести. Профессиональный деятель рынка должен обладать широким набором знаний и умений. Следовательно, маркетинг комплексная система организации производства и сбыта продукции, ориентированная на удовлетворение потребностей конкретных потребителей и получение прибыли на основе исследования и прогнозирования рынка, изучения внутренней и внешней среды предприятияэкспортера, разработки стратегии и тактики поведения на рынке с помощью маркетинговых программ. В этих программах заложены мероприятия по улучшению товара и его ассортимента, изучению покупателей, конкурентов и конкуренции по обеспечению ценовой политики, формированию спроса, стимулированию сбыта и рекламы, оптимизации каналов товародвижения и организации сбыта, организации технического сервиса и расширения ассортимента представляемых сервисных услуг. Маркетинг как порождение рыночной экономики является в определенном смысле философией производства, полностью подчиненной условиям и требованиям рынка, находящимся в постоянном динамическом развитии под воздействием широкого спектра экономических, политических, научно - технических и социальных факторов. Предприятия - производители и экспортёры рассматривают маркетинг как средство для достижения целей, фиксированных на данный период по каждому конкретному рынку и его сегментам, с наивысшей экономической эффективностью. Однако это становится реально тогда, когда производитель располагает возможностью систематически корректировать свои научнотехнические, производственные и сбытовые планы в соответствии с изменениями рыночной конъюнктуры, маневрировать собственными материальными и интеллектуальными ресурсами, чтобы обеспечить необходимую гибкость в решении стратегических и тактических задач, исходя из результатов маркетинговых исследований. При этих условиях маркетинг становится фундаментом для долгосрочного и оперативного планирования производственно-коммерческой деятельности, составления экспортных программ производства, организации научно-технической, инвестиционной и сбытовой работы предприятия, а управление маркетингом - важнейшим элементом системы управления предприятием.

Маркетинговая деятельность должно обеспечить надежную и своевременную информацию о рынке, структуре и динамике спроса, вкусах покупателей, то есть информацию о внешних условиях фирмы, создание такого товара, набора товаров, который более полно удовлетворяет требованиям рынка, чем конкуренты, необходимое воздействие на потребителя, на спрос, и на рынок, обеспечивающее максимально возможный контроль сферы реализации. В основе деятельности производителей, работающих на основе принципов маркетинга, лежит девиз: производить только то, что требуют рынок и покупатель. Отсюда сущность маркетинга состоит в следующем: следует производить то, что, безусловно, найдёт сбыт, а не пытаться навязать покупателю “несогласованную” предварительно с рынком товар. В периоды стабилизации или роста экономики предприниматель вынужден ориентироваться на требования рынка, изучать закономерности и тенденции покупательского спроса, учитывать интересы потребителей, осваивать методы конкурентной борьбы, применять маркетинговые инструменты стимулирования сбыта и продажи товаров, то есть опираться в своей коммерческой деятельности на стратегию маркетинга. Методы маркетинговой деятельности заключаются в проведении анализа внешней среды, в которую входят не только рынок, но и политические, социальные и иные условия, анализ потребителей, как реальных, так и потенциальных.

Данный анализ заключается в исследовании демографических, экономических, социальных и иных характеристик людей, принимающих решение о покупке, а также их потребностей в широком смысле этого понятия и процессов приобретения ими как нашего, так и конкурирующих товаров, изучение существующих и планирование будущих товаров, то есть разработка концепции создания новых товаров и модернизация старых, включая их ассортимент, упаковку, планирования товародвижения и сбыта, включая создание соответствующих 
собственных сбытовых сетей со складами и магазинами, обеспечение формирования спроса и стимулирование сбыта путем комбинации рекламы, личной продажи, «паблик рилейшнз» и иных стимулов, обеспечение ценовой политики, заключающихся в планировании систем и уровней цен на поставляемые товары, определение технологии использования цен, кредитов, скидок, управление маркетинговой деятельностью как системой, то есть планирования, выполнение и контроль маркетинговой программы и индивидуальных обязанностей каждого участника работы предприятия, оценка рисков и прибылей, эффективности маркетинговых решений. Маркетинг выражается в трех направлениях, а именно маркетинг - микс, поведение потребителей на рынке и маркетинговые стратегии.

Маркетинг-микс - это набор маркетинговых средств, определенная структура которого обеспечивает решение маркетинговых задач на целевом рынке. Предприятия должны разработать комплекс маркетинга, то есть комплекс маркетинговых стратегий побуждающих потребителей покупать их товары и услуги. Все решения относительно составляющих комплекса маркетинга во многом зависят от принятого предприятием конкретного позиционирования товара. Комплекс маркетинга часто называют четырьмя "Р" маркетинга: Product (товар), Price ( цена, ) Place место, распределение, Promotion (продвижение).

Товар комплекса маркетинга гарантирует, что его характеристики обеспечивают удовлетворенность потребностей потребителей. Это набор «изделий и услуг», которые предприятие предлагает целевому рынку, все что может удовлетворить нужду или потребность и предлагается рынку с целью привлечения внимания, приобретения, использования или потребления. Это могут быть физические объекты, услуги, место, организации и идеи. Классификации товаров является полезной, так как она позволяет фирме очень четко формулировать свои цены, ставить задачи в маркетинговой деятельности и оценивать успехи и неудачи.

Цена -денежное выражение стоимости товара. В системе маркетинга является средством донесения до потребителей ценности полезных свойств товара, удовлетворяющих их нужды. Находится в тесной взаимосвязи со всеми элементами комплекса маркетинга. Находится в тесной взаимосвязи со всеми элементами комплекса маркетинга. В области ценовой политики маркетинговые решения связаны с формированием общего восприятия товара и его позиционированием в глазах потенциальных покупателей, с определением места и роли цены в получение конкурентных преимуществ, с установлением, изменением и снижением цен, основанными на экономическом и психологическом аспектах его восприятия. Цена, единственный элемент маркетинга, обеспечивающий предприятию реальный доход. Правильное определение цены позволяет увеличить рентабельность производства, повысить конкурентоспособность предприятия и товара на рынке, освоить более широкий сегмент рынка, поднять уровень устойчивости и стабильности функционирования предприятия на рынке. Цена должна соответствовать качеству товара. Если она завышена, потребители решать, что они не получать эквивалент за уплаченные деньги. Если цена слишком низкая, потребители поставят под сомнение качество товара.

Распределение - обеспечение доступности товаров для потребителей на основе доведения нужных товаров в нужное место и в нужное время. Распределительная политика охватывает вопросы планирования возможных объемов продаж, формирование каналов распределения, организации продаж. Цель распределительной политики заключается в обеспечение доступности товаров для потребителей. Для этого, необходимо точно выявить потребность целевого рынка в товарах и спланировать возможные размеры их продажи, сформировать эффективные каналы распределения и быстрее довести свою продукцию до потребителя. Для этого необходимо: во-первых, точно выявить потребность целевого рынка в товарах и спланировать возможные размеры их продажи;

во-вторых, сформировать эффективные каналы распределения и быстрее довести свою продукцию до потребителя;

в-третьих, создать максимум условий для быстрой «встречи» товара с покупателями.

Выявление потребностей и планирование продаж производится путем исследования спроса, состояния рынка и торговой конъюнктуры.

Канал распределения представляет собой совокупность промежуточных звеньев, вовлеченных в процессе продвижения товаров с целью обеспечения их доступности для конечных потребителей. В процессе промежуточных звеньев могут выступать простые посредники, оптовые и розничные торговцы. Функции каналов распределения является: обеспечение доступности товаров в достаточном числе мест, что предполагает формирование каналов распределения с учетом рыночных условий, характера продукта и реальных возможностей предприятия (выбор посредников, исследования, оценка рисков и другие). Физическое перемещение товаров (маркетинговая логистика) связанное с организацией движения материальных потоков по выбранным каналам распределения (складирование, транспортировка, прием и обработка заказов, упаковка отгрузка и другие). Каналы распределения можно охарактеризовать по числу составляющих их уровней. Уровень канала распределения - это любой посредник, который выполняет ту или иную работу по приближению товара и права собственности на него к конечному покупателю.

Мы определили маркетинг как совокупность действий, направленных на выявление и удовлетворение потребностей потребителю. Согласно приведенному определению, понимание запросов потребителей имеет 
решающее значения при выявлении маркетинговых возможностей разработке и стратегий по реализации этих возможностей. Недостаточное понимание потребителя ставит компанию в невыгодное положение, а иногда на грань катастрофы. Чтобы понять своих потребителей, компаниям надо проводить маркетинговые исследования для выявления потребностей потребителя, их восприятие существующих марок товаров и отношения к маркам. В прошлом деятели рынка учились понимать своих потребителей в процессе повседневных торгового общения с ними. Но рост размеров фирм и рынков лишили многих распределителей маркетинга непосредственных контактов со своими клиентами. Управляющим приходилось прибегать к исследованию потребителя. Фирма разобравшаяся в том, как реагируют потребители на различные характеристики товара, цены, рекламные аргументы будет иметь огромное преимущество перед конкурентами. Отправной точкой всех этих усилий является простая модель покупательского поведения.

Побудительные факторы маркетинга включают в себя четыре элемента: товар, цену, методы распространения и стимулирования. Прочие раздражители слагаются из основных сил и событий из окружения покупателя: экономической, научно-технической, политической и культурной среды. Пройдя через «черный ящик» сознания покупателя, все обусловлены на эти раздражители вызывают ряд поддающихся наблюдению покупательских реакций: выбор дилера, выбор времени покупки, выбор объёма покупки.

Потребители подвержены воздействия различных стимулов маркетинга то есть связанных с покупкой товара сообщений, призванных оказать влияние на потребителей. Такими стимулами могут быть сами товары, реклама, внутри магазинное стимулирование, цены, отзывы друзей и родственников. Такие сообщения обычно оказывают на потребителей большое влияние, чем стратегия маркетинга, то есть их считают заслуживающими большего доверия. Реакция потребителей на эти стимулы обусловлены наличием трех видов факторов:

- психологические факторы, или общий психологический настрой по отношению к объекту. Психологические состояние потребителя определяет положительную или отрицательную реакцию на марку товара;

- индивидуальные характеристики потребителя то есть демографические факторы, образ жизни, личностные особенности;

- внешние факторы, которые включают в себя культуру и принадлежность потребителя к социальному классу. Они включают в себе более специфические личностные влияния, например семейные традиции, влияние референтных групп, то есть групп, к которым потребитель обращается за советом, мнением.

Стратегия, как обобщающая модель действия, необходима для достижения поставленных целей путем координации и распределения ресурсов компании. По мере развития рыночных отношений в Республике Узбекистан и нормализации самого рынка маркетинг превращается в рыночную концепцию управления предприятием, в систему при которой в основе принятия практически всех решений будет иметь важное значение информация поступающая с рынка. С переходом на «рынок покупателя» конкурентоспособность предприятия во всё возрастающей степени зависит от того, насколько усовершенствован его маркетинг. Цель каждой компании добиться коммерческого успеха. Для процветания компании имеют значение многие факторы: правильно выбранная стратегия, преданные компании служащие, хорошо наложенная система информирования, точное выполнение программы маркетинга. Сегоднящние преуспевающие компании на всех уровнях имеют одну общую черту - они ориентированы на потребителя и всю работу строять на основе маркетинга. Основная цель- это понимание и удовлетворение нужд потребителя на четко обозначенных целевых рынках. Служащие компании должны создавать наивысшую потребительскую ценность, обеспечивая полное удовлетворение потребностей клиентов. Именно использование такого подхода в деятельности предприятия позволит получить желаемую долю и прибыль.

\section{Список литературы}

1. Котлер Ф. Основы маркетинга. Учебное пособие.-М.:Издательский дом «Вильямс», 2012.-656с.

2. Парамонова Т.Н. Маркетинг. Учебное пособие.-М.:КНОРУС,2010.-190с.

3. Соловьев Б.А., Мешков А.А., Мусатов Б.В. Маркетинг. Учебник.-М.: ИНФРА-М, 2010.-336с.

4. Басовский Л.Е. Маркетинг. Учебное пособие.-М.:ИНФРА-М. 2010.-219с.

5. Беляев В.И. Маркетинг: основы теории и практики: Учебник.- М.: КНОРУС, 2010.-680с.

6. Бронникова Т.С. Маркетинг: теория, практика. Учебное пособие. М.: КНОРУС, 2010.-208c.

7. Уолкер О. Маркетинговая стратегия. Учебное пособие.-М.: Вершина, 2008.-384c.

8. Ricky W.Griffin. Fundamentals of Management. Eighth Edition. 2015 Cengage Learning products are represented in Canada by Nelson Education, Ltd.p. 547

9. Gary Armstrong, Philip Kotler, Michael Harker, Ross Brennan. Marketing an introduction. England, 2016, Paperback: 720 pages, Pearson

10. Patrick De Pelsmacker, Maggie Geuens and Joeri Van den Bergh. Marketing communications: a European perspective Fifth edition. Pearson Education Limited 2013. -614 pages

11. Nigel Bradley Marketing research: tools \& techniques. 3-rd edition 2013. 548 pages

12. Ассэль Генри Маркетинг: принципы и стратегия. ИНФРА-М,1999. -803c. 